\title{
IMPLEMENTASI SINKRONASI DATABASE SQL DENGAN REPLIKASI PADA APLIKASI FINANCE PT.XYZ
}

\author{
Muhammad Firdaus Abdi' ${ }^{1)}$, Agung Susanto ${ }^{2)}$, Ema Utami ${ }^{3)}$, Kusnawi ${ }^{4)}$ \\ ${ }^{1}$ Magister Teknik Informatika, Universitas AMIKOM Yogyakarta \\ mfirdaus.abdi29@gmail.com \\ ${ }^{2}$ Magister Teknik Informatika, Universitas AMIKOM Yogyakarta \\ agung12022170@gmail.com \\ ${ }^{3}$ Universitas AMIKOM Yogyakarta \\ ema_u@amikom.ac.id \\ ${ }^{4}$ Universitas AMIKOM Yogyakarta \\ kusnawi@amikom.ac.id
}

\begin{abstract}
Databases or databases in their development must be managed properly, especially now that the database contains important data information of a company that must be protected from data loss so that a system is needed to back up the data. On the other hand, when an application owned by a company has two sites, site A and site B, which are connected to each other, so a system is needed to handle when one place experiences a problem the application can work and when the system is running well the data on site $A$ and site $B$ have data same. This research tries to implement a data replication system, where data site $A$ and site $B$ will be linked, then data replication will be carried out with a database synchronization system. The results of this implementation were successfully carried out, but to ensure the data replication process was successful, other tests were carried out such as deleting data, editing data, changing data, from this test everything was successfully synchronized between site A and site B so that the data owned was the same between sites, tests were carried out processed in the form of a percentage of success in order to obtain a database synchronization process with $100 \%$ data replication, for that this replication can be applied to business processes at the company PT. XYZ in the handling of managed database systems.
\end{abstract}

Keywords - SQL Server, Data Replication, Database, Data, SQL

\begin{abstract}
Abstrak
Database atau basisdata pada perkembangannya harus dikelola dengan baik, apalagi saat ini database yang didalamnya memiliki informasi data penting sebuah perusahaan yang harus dilindungi dari hilangnya data sehingga diperlukannya sistem untuk membackup data tersebut. Disisi lain ketika sebuah aplikasi yang dimiliki perusahaan memiliki dua tempat site A dan site B yang dimana saling terhubung sehingga diperlukan sistem untuk menangani ketika satu tempat mengalami gangguan aplikasi itu dapat berkerja dan ketika sistem sudah berjalan baik data pada site A dan site B memiliki data yang sama. Penelitian ini mencoba mengimplementasikan sistem replikasi data, yang dimana data site A dan site $B$ akan dihubungkan, selanjutnya akan dilakukan replikasi data dengan sistem sinkronisasi database. Hasil dari implementasi ini berhasil dilakukan akan tetapi untuk memastikan proses replikasi data berhasil dilakukan pengujian lain seperti penghapusan data, edit data, ubah data, dari pengujian ini semua berhasil sinkron antara site A dan site B sehingga data yang dimiliki sama antar site, pengujian yang dilakukan diolah dalam bentuk persentasi keberhasilan sehingga didapat proses sinkronisasi database dengan replikasi data 100\%, untuk itu replikasi ini dapat terapkan untuk proses bisnis pada perusahaan PT. XYZ dalam penanganan sistem database yang dikelola.
\end{abstract}

Kata Kunci - SQL Server, Replikasi Data, Database, Data, SQL

\section{PENDAHULUAN}

Basis data dari perkembangannya beragam bentuk dan teknologi yang diterapkan dalam penggunaan dan akses data (AAN SAID DAROINI, 2016), database Structured Query Language (SQL)(Agarwal, Sarthak and Rajan, 2017) banyak menjadi pilihan perusahaan- 
perusahaan untuk menjadi solusi sebagai proses dan penyimpanan data yang dimana perusahaan memiliki aplikasi sendiri dan menggunakan server sendiri yang digunakan untuk mengolah data (Srivastava, Goyal and Kumar, 2016), dikarenakan data tersebut dikelola sendiri sehingga data menjadi sebuah aset yang berharga untuk dijaga. Sebuah data ( $\mathrm{Lv}$ et al., 2020) menjadi faktor penting dalam sebuah proses bisnis perusahaan, ketika tidak adanya sebuah data maka informasi (Susanto and Meiryani, 2019) yang dicari untuk melakukan sebuah keputusan sebuah perusahan tidak bisa didapat. Untuk memenuhi ketersedian sebuah data pada server (Gyorodi et al., 2019), ada beberapa cara atau teknik dalam penyalinan ( $\mathrm{Ni}$ et al., 2019), penyimpanan (Banawan and Ulukus, 2018) sebuah data, salah satunya dengan replikasi (Mealha et al., 2019) yang berfungsi melakukan sinkronisasi antar basis data sehingga data dapat tersedia.

Dalam permasalahan kali ini sebuah perusahaan PT.XYZ mememiliki 2 kantor A dan $\mathrm{B}$, aplikasi yang digunakan yaitu aplikasi Finance yang dimana aplikasi tersebut dapat diakses dari kantor A dan B, masalah timbul ketika kantor B akses internetnya lambat atau mati sehingga kantor B tidak bisa menggunakan aplikasi finance tersebut dan proses bisnis sebuah perushaan akan terhambat dikarenakan inputan sebuah data tidak bisa dilakukan.

Berdasarkan dari masalah tersebut penelitian kali ini mencoba menerapkan replikasi database(Castro-Medina et al., 2020) untuk mensolusi ketika kantor B internetnya mati atau lambat masih bisa akses data yang sama dengan menyimpan data secara lokal dan ketika internetnya berjalan baik, maka akan dilakukan replikasi untuk sinkronisasi data (Pendse et al., 2020) untuk menyamakan data antara kantor $A$ dan Kantor B, dan juga berfungsi agar inputan data tersebut tidak hilang atau tidak tersimpan.

Hasil penelitian ini nantinya diharapkan sistem dapat memiliki backup data ketika salah satu jaringan bermasalah, sehingga sistem masih berjalan normal, ketika sistem sistem berjalan dengan normal maka database akan otomatis terupdate pada server dengan sistem replikasi sinkronisasi data yang dilakukan.

\section{METODE PENELITIAN}

Penelitian ini melakukan 6 tahapan yang dimana setiap tahapan dilakukan untuk menghasilkan replikasi sebuah database yang digunakan pada aplikasi finance.

Tahapan yang dilakukan diantaranya : analisa sistem, analisa kebutuhan hardware dan software, penentuan database yang digunakan, tahapan konfigurasi, implementasi replikasi, dan hasil replikasi.

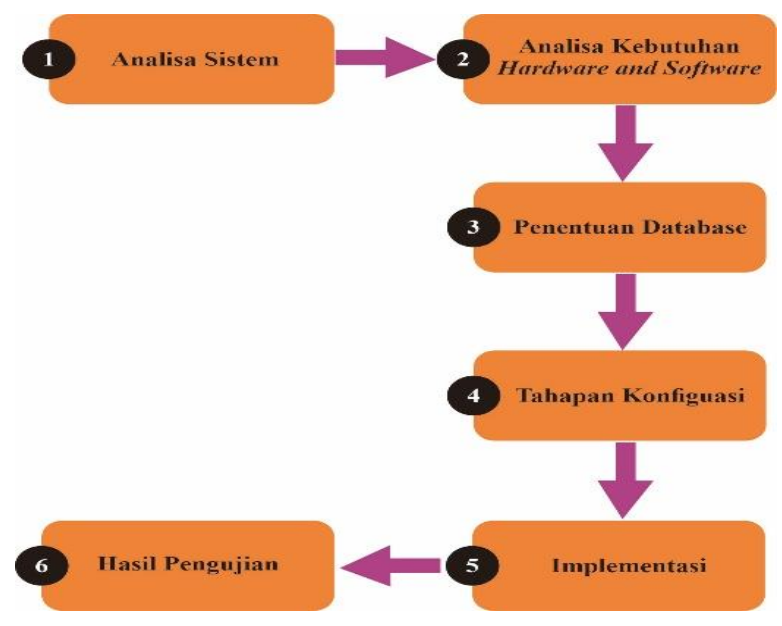

Gambar 1. Alur Penelitian

\section{A. Analisa Sistem}

Dalam tahapan penelitian ini dilakukan analisa batasan lingkup sistem dari pengujian yang dimana bagaimana menerapkan replikasi database pada site A yang terhubung dengan site B.

\section{B. Analisa Kebutuhan Hardware and Software}

Tahapan ini analisa tentang kebutuhan perangkat lunak dan perangkat keras yang dibutuhkan untuk menjalankan sebuah replikasi data.

Tabel 1. Kebutuhan Perangkat Lunak

\begin{tabular}{|c|l|l|}
\hline No. & \multicolumn{1}{|c|}{$\begin{array}{c}\text { Perangkat } \\
\text { Lunak }\end{array}$} & \multicolumn{1}{c|}{ Versi } \\
\hline 1 & Sistem operasi & $\begin{array}{l}\text { Windows Server } \\
2008\end{array}$ \\
\hline 2 & Database & SQL Server 2017 \\
\hline
\end{tabular}

Tabel 2. Kebuthan Perangkat Keras

\begin{tabular}{|c|c|l|}
\hline No. & \multicolumn{1}{|c|}{$\begin{array}{c}\text { Perangkat } \\
\text { Lunak }\end{array}$} & \multicolumn{1}{c|}{ Versi } \\
\hline & & Intel(R) Xeon(R) CPU \\
1 & Prosesor & E3-1220 v3 @ 3.10 \\
& & GHz 3.10GHz \\
\hline
\end{tabular}




\begin{tabular}{|c|l|l|}
2 & $\begin{array}{l}\text { Penyimpanan } \\
\text { (RAM) }\end{array}$ & 8 GB DDR4 \\
\hline 3 & Hardisk & $1 \mathrm{~TB}$ \\
\hline 4 & Grafis & Intel(R) \\
\hline
\end{tabular}

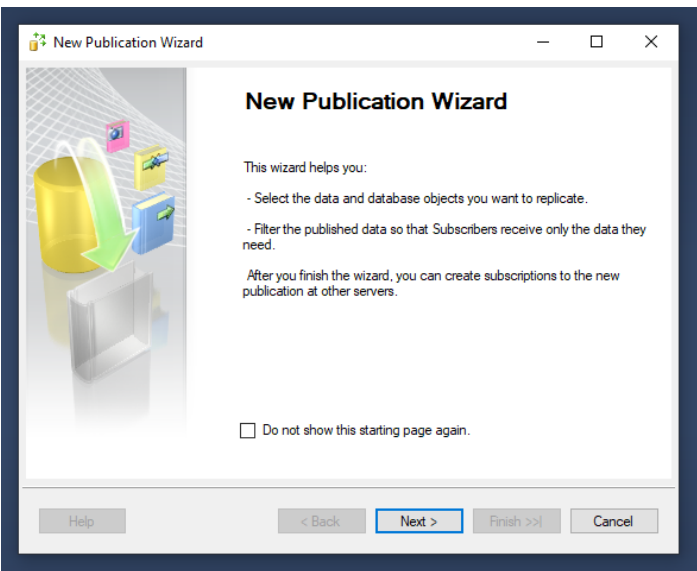

C. Penentuan Database

Database yang digunakan adalah database pada aplikasi finance, aplikasi ini menjalankan sistem keuangan pada perusahaan PT.XYZ dimana database ini berbasis SQL Server. Database inilah yang akan digunakan untuk dilakukan replikasi agar site A dan site B memiliki database yang sama.

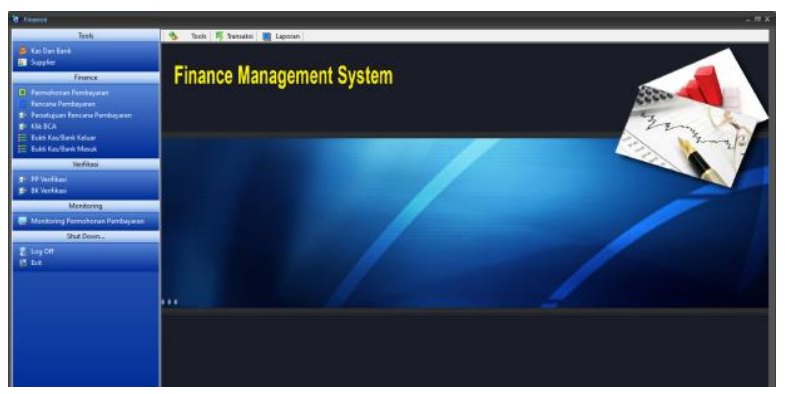

Gambar 2. Aplikasi Finance

\section{Tahapan Konfigurasi}

Konfirgurasi yang akan dilakukan pada penelitian ini seperti ditunjukkan pada gambar ini.

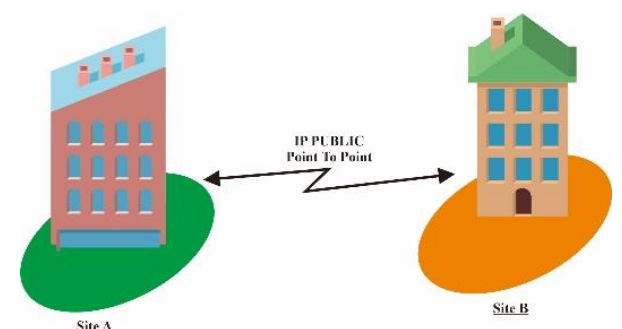

Gambar 3. Hubungan antara site A dan B

Selanjutnya tahapan dlakukan meliputi memilih database yang akan dipublikasi.

Gambar 4. Konfigurasi publikasi database

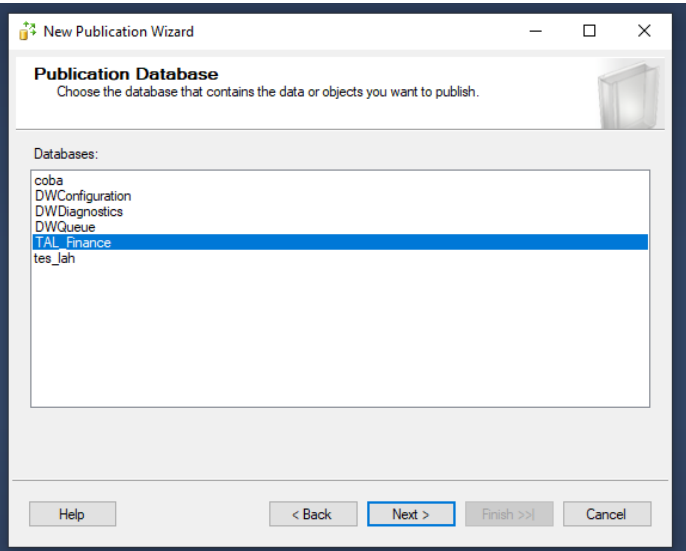

Gambar 5. Pemilihan database

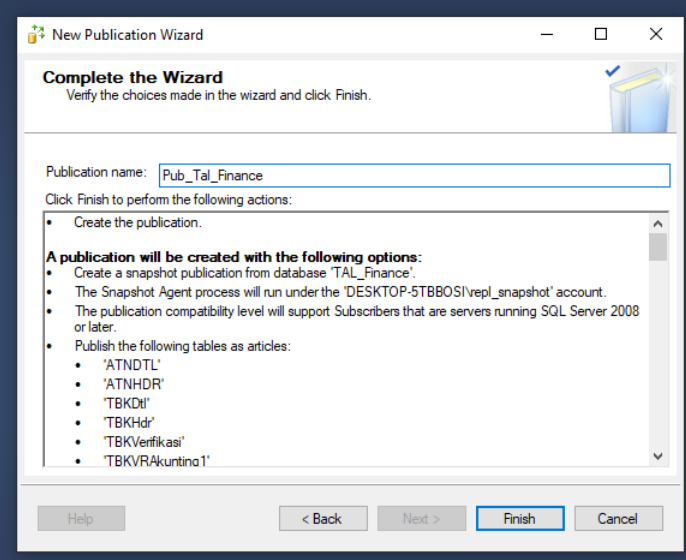

Gambar 6. Penentuan nama publikasi 


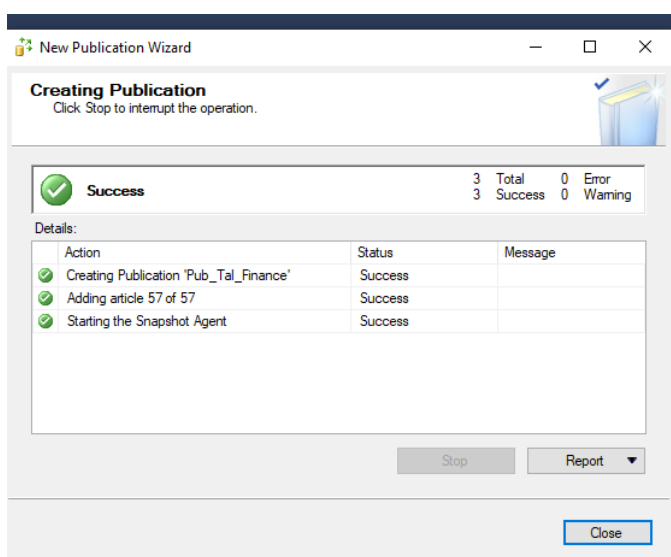

Gambar 7. Hasil membuat database publikasi

Dari gambar diatas ada hasil memilih dan membuat database untuk dipublikasi, langkah awal ini adalah langkah penentu proses dari replikasi sebuah database SQL Server, dari proses ini akan dilajutkan ke proses implemetasi proses replikasi data.

E. Tahapan Implementasi

Proses implementasi ini meliputi proses pembuatan replikasi database yang ada pada site A yang dihubungkan dengan site $\mathrm{B}$

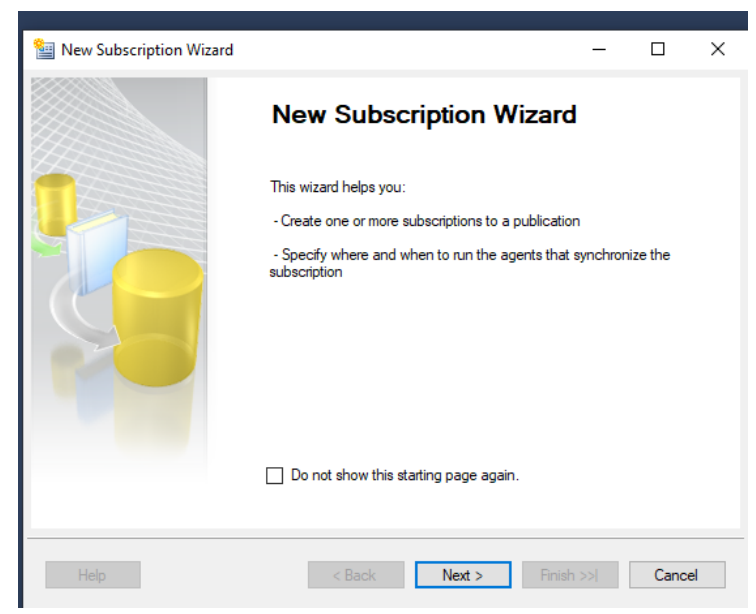

Gambar 8. Konfigurasi Replikasi

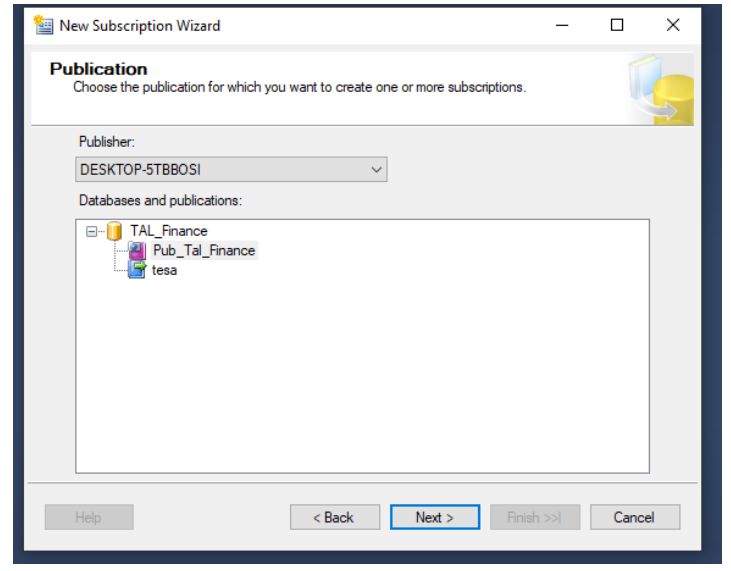

Gambar 9. Memilih publikasi yang telah dibuat

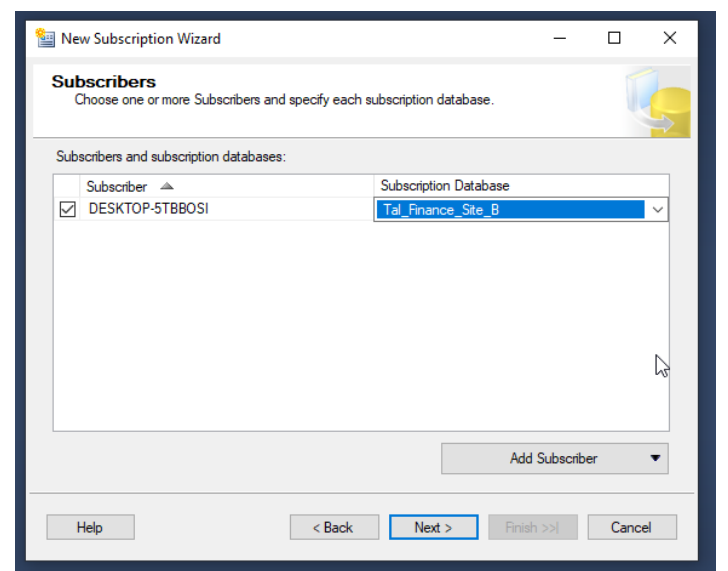

Gambar 10. Menghubungkan dengan database site $\mathrm{B}$

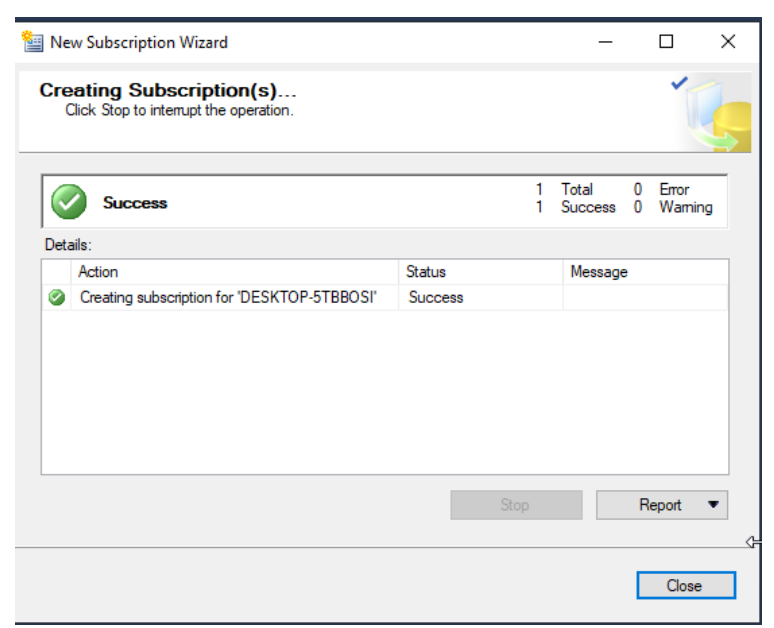

Gambar 11. Hasil replikasi data

Gambar diatas menunjukkan replikasi telah berhasil dilakukan dengan menghubungkan database site A dan database site B.

\section{HASIL DAN PEMBAHASAN}

3.1. Hasil pengujian 
Pengujian ini dari penelitian ini adalah menguji hasil dari proses replikasi database yang telah dibuat apakah berhasil dijalankan sesuai dengan konsep awal penelitian yang akan dilakukan. Berikut adalah hasil dan proses dari singkronasi replikasi data.

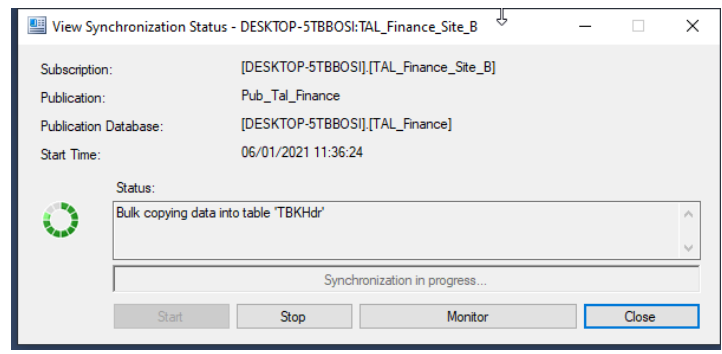

Gambar 12. Proses replikasi database

Proses ini dijalankan untuk mengetahui hasil dari proses replikasi antara database site A dan site $\mathrm{B}$.

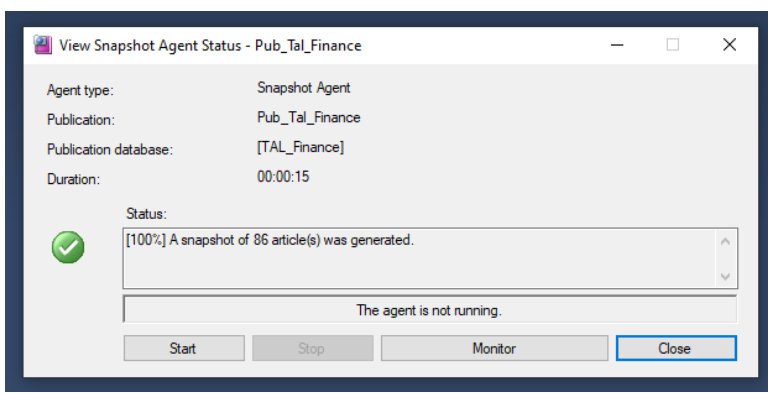

Gambar 13. Hasil replikasi database

Dari gambar diatas database pada site A berhasil di replikasi sebanyak 83 artikel atau tabel ke site $\mathrm{B}$, sehingga site A dan site B sekarang memiliki database yang sama.

a) Pengujian dengen menghapus data pada site A, apakah database site B juga ikut berubah.

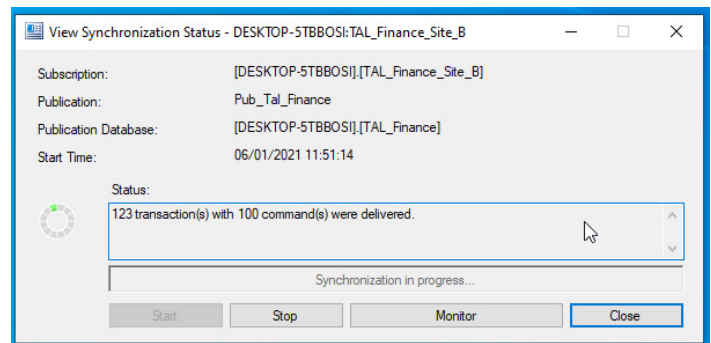

Gambar 14. Singkronasi data

Dari pengujian yang dilakukan ketika data site A berubah maka sistem secara otomatis mengirim perubahan pada site $B$, begitu pula sebaliknya sehingga data site A dan site B memiliki data yang sama. b) Pengujian dengen penambahan data pada site A, apakah database site B juga ikut bertambah.

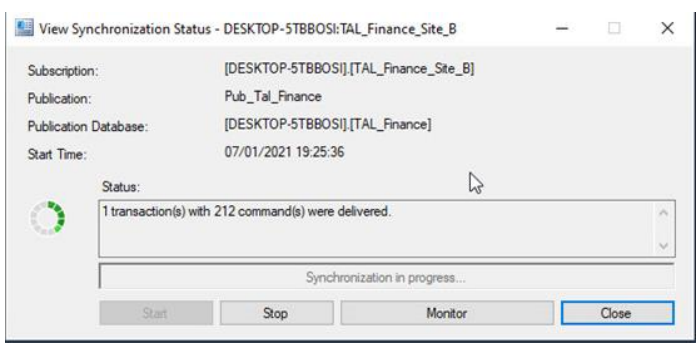

Gambar 15. Singkronasi penambahan data

Dari proses penambahan data proses singkronasi dari site A ke site B dari pengujian berhasil dilakukan.

c) Pengujian dengen mengedit data pada site A, apakah database site B juga ikut terubah.

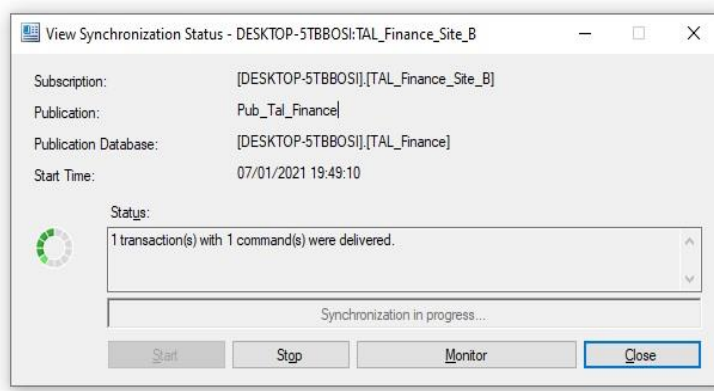

Gambar 16. Singkronasi ketika edit data

Dari proses mengubah atau mengedit data sistem otomatis melakukan proses singkronasi dari site A ke site B dan proses singkronasi dari pengujian berhasil dilakukan.

Tabel 3. Persentasi keberhasilan proses Replikasi database

\begin{tabular}{|c|l|c|c|}
\hline No. & $\begin{array}{c}\text { Pengujian } \\
\text { Sinkronisasi data } \\
\text { dengan Replikasi }\end{array}$ & $\begin{array}{c}\text { Berhasil } \\
\text { dilakukan } \\
\text { (ya/tidak) }\end{array}$ & $\begin{array}{c}\text { Persentasi } \\
\text { keberhaslian }\end{array}$ \\
\hline 1 & Data site A ke site B & ya & $100 \%$ \\
\hline 2 & Hapus data & ya & $100 \%$ \\
\hline 3 & Tambah data & ya & $100 \%$ \\
\hline 4 & Edit data & ya & $100 \%$ \\
\hline
\end{tabular}

Tabel ini menyajikan persentasi keberhasilan singkronasi data dari proses replikasi data, dimana data yang berubah akan dilakukan singkronasi agar data pada site A dan site B sama, dan dari tabel diatas bisa dikatakan bahwa proses replikasi database aplikasi finance pada PT. XYZ 
ini berhasil diterapkan atau dilakukan dengan tingkat keberhasilan $100 \%$ sehingga replikasi data ini dapat diterapkan dalam sistem perusahaan PT. $\mathrm{XYZ}$ ini untuk mendukung proses bisnis perusahaan.

\section{KESIMPULAN}

Dari penelitian ini diterapkannya proses singkronasi data bisa dikatakan berhasil untuk menghubungkan database site $\mathrm{A}$ dan site $\mathrm{B}$ agar memiliki database yang sama, dan menanggunalangi ketika salah satu sistem bermaslah agar aplikasi bisa terus tetap berjalan. Dalam menguji singkronasi database dengan replikasi data ini, peneliti melakukan replikasi seluruh data site $\mathrm{A}$ ke site $\mathrm{B}$, menghapus data, edit data, tambah data, dari pengujian ini proses singkronasi data berhasil dilakukan dengan persentasi keberhasilan $100 \%$.

Untuk usulan penelitian selanjutnya bisa dengan metode yang berbeda, bisa membandingkan mirroring data dengan replikasi data.

\section{REFERENSI}

\section{A. Artikel Jurnal}

AAN SAID DAROINI, A. (2016) 'PERBANDINGAN PENGGUNAAN NOSQL MONGODB DAN MYSQL PADA BASIS DATA FORUM KOMUNIKASI', Jurnal Manajemen Informatika.

Agarwal, Sarthak and Rajan, K. (2017) 'Analyzing the performance of NoSQL vs. SQL databases for Spatial and Aggregate queries', Free and Open Source Software for Geospatial (FOSS4G) Conference Proceedings. doi: https://doi.org/10.7275/R5736P26.

Banawan, K. and Ulukus, S. (2018) 'The capacity of private information retrieval from coded databases', in IEEE Transactions on Information Theory. doi: 10.1109/TIT.2018.2791994.

Castro-Medina, F. et al. (2020) 'FRAGMENT: A Web Application for Database Fragmentation, Allocation and Replication over a Cloud Environment', IEEE Latin America Transactions. doi: 10.1109/TLA.2020.9099751.

Gyorodi, R. et al. (2019) 'Performance of OnPrem Versus Azure SQL Server: A Case Study', IEEE Access. doi: 10.1109/ACCESS.2019.2893333.

Lv, Z. et al. (2020) 'BIM Big Data Storage in WebVRGIS', IEEE Transactions on Industrial Informatics. doi: 10.1109/TII.2019.2916689.
Mealha, D. et al. (2019) 'Data replication on the cloud/edge', in Proceedings of the 6th Workshop on Principles and Practice of Consistency for Distributed Data, PaPoC 2019. doi: 10.1145/3301419.3323973.

Ni, F. et al. (2019) 'Leveraging SSD's flexible address mapping to accelerate data copy operations', in Proceedings - 21 st IEEE International Conference on High Performance Computing and Communications, 17th IEEE International Conference on Smart City and 5th IEEE International Conference on Data Science and Systems, HPCC/SmartCity/DSS 2019. doi: 10.1109/HPCC/SmartCity/DSS.2019.00150.

Pendse, S. et al. (2020) 'Oracle database in-memory on active data guard: Real-time analytics on a standby database', in Proceedings - International Conference on Data Engineering. doi:

10.1109/ICDE48307.2020.00139.

Srivastava, P. P., Goyal, S. and Kumar, A. (2016)

'Analysis of various NoSql database', in Proceedings of the 2015 International Conference on Green Computing and Internet of Things, ICGCIoT 2015. doi: 10.1109/ICGCIoT.2015.7380523.

Susanto, A. and Meiryani (2019) 'Database management system', International Journal of Scientific and Technology Research. doi: 10.5120/179310. 